\title{
INCREASING MATERIAL AND ENERGY RECOVERY FROM WASTE FACILITIES: HUMAN HEALTH AND ECOSYSTEM QUALITY IMPLICATIONS
}

\author{
Federico Sisani ${ }^{1, *}$, Amani Maalouf ${ }^{2}$, Francesco Di Maria ${ }^{1}$, Marzio Lasagni ${ }^{3}$ and \\ Mutasem El-Fadel ${ }^{2}$ \\ ${ }^{1}$ Università degli Studi di Perugia, Industrial Engineering, Perugia, Italy \\ ${ }^{2}$ American University of Beirut, Department of Civil and Environmental Engineering, Beirut, Lebanon \\ ${ }^{3}$ AISA Impianti Spa, Arezzo, Arezzo, Italy
}

Article Info:
Received:
29 October 2018
Revised:
19 February 2019
Accepted:
22 February 2019
Available online:
31 March 2019
Keywords:
Human health
Ecosystem quality
Life cycle assessment
Material recovery
Energy recovery

Article Info:

29 October 2018

Revised:

Accepted:

2 February 2019

31 March 2019

Ecosystem quality

Material recovery

Energy recovery

(a)

\begin{abstract}
This study presents a preliminary assessment of the implications on human health and ecosystem quality arising from increased materials and energy recovery from waste. Two scenarios were assessed encompassing different methods of waste distribution and elements of an integrated waste management system (composting, anaerobic digestion coupled with bio-methane recovery, incineration, and landfilling). The base scenario involved processing about 100,000 tonnes of municipal solid waste (MSW) per year and the modified scenario processed about 140,000 tonnes of MSW per year. The analysis was conducted following a life cycle approach using both midpoint and endpoint indicators. Based on a single tonne of waste processed, the results indicated lower $(\sim 66 \%)$ human toxicity with cancer and non-cancer effects (CTUh) and impact on human health (DALY) ( 64\% lower) for the modified scenario. Decrease in landfilling and increase in the recovery of the organic fraction from separated collection (OFSC) for biological treatment in the form of composting and anaerobic digestion in the modified scenario were the main drivers of these results. Considering savings in emissions from substituting the production of mineral fertilizers, the values of ecosystem quality (PDF* $m^{2 *}$ year) indicated a lower impact ( $86 \%)$ for the modified scenario.
\end{abstract}

\section{INTRODUCTION}

Decisions about solid waste management (SWM) invariably take into account waste minimization, collection, separation, and treatment. In this context, the EU Waste Framework Directive (2008) has long recognized the basic concepts associated with SWM, such as reuse, recycle, and recovery of material and energy. In addition, it classifies SWM into a hierarchy that emphasizes the best use of the waste materials for replacing and/or avoiding the consumption of raw materials and fossil fuels. This concept aims at preventing the depletion of global resources and augmenting sustainable development. Direct combustion coupled with energy recovery has become one of the most effective and widespread practices in the EU area for SWM. Globally, about 600 municipal solid waste incineration (MSWI) facilities are operating, of which 430 are located in the EU28 (Cheng and Hu, 2010; Grosso et al., 2010). In 2016, in the EU28, around 68 Mtonnes of waste were incinerated with energy recovery, which is equiva- lent to around $30 \%$ of the total amount of MSW generated (ISPRA, 2018).

Nevertheless, MSWI performed at a low efficiency without energy recovery is considered, according to current EU legislation (Waste Framework Directive, 2008), a disposal operation (not aimed at replacing other material). On the other hand, if performed at high energy efficiency, MSWI can be considered a good approach as a recovery operation, principally for fuel or energy generation, replacing other raw materials in compliance with the implementation of the SWM hierarchy.

Ever since the first EU directive on waste, the protection of human health has been a priority in the SWM, also including environmental protection in its broader meaning. However, the waste hierarchy needs to be carefully analyzed, because different waste management contexts and solutions can cause different environmental impacts (El-Fadel et al., 1997; Buttol et al., 2007; McDougall et al., 2001). In this context, there is need for a more in-depth evaluation, taking into account the associated impacts from increased 
material, energy, and fuel recovery from an integrated waste management system.

Recent studies have focused more attention on health risks in order to identify the potential impacts of operating MSWIs (Ma et al., 2018; Rovira et al., 2018; Deng et al., 2016; Candela et al., 2015; Cangialosi et al., 2008; Karademir, 2004; Ni et al., 2014; Ranzi et al., 2013; Reis et al., 2007; Schuhmacher et al., 2002). The results of some of these studies proposed relationships between emissions from MSWI and health effects, specifically adverse effects on reproduction and cancer (Candela et al., 2015). Nevertheless, it is difficult to interpret these findings and make a conclusive statement due to numerous sources of exposure such as diet, air pollution, and dental amalgam, as well as genetic factors that may also impact the responses of individuals differently.

The performance of existing waste treatment plants has been extensively reported in life cycle assessment (LCA) studies (Di Maria et al., 2018; Di Maria and Sisani, 2018; Bonoli et al., 2004; Morselli et al., 2007) and different waste management processes have been compared (Arena et al., 2003; Buttol et al., 2007; Cherubini et al., 2008; Liamsanguan and Gheewala, 2007). The aim of the present study was to assess the effects on human health and ecosystem quality of an increased amount of waste processed for recycling and energy recovery in an existing integrated waste treatment plant, which was not assessed in previous studies. The increase in recycling and recovery also entails the adoption of new technologies, mainly based on biological treatment of the organic fraction.

\section{MATERIALS AND METHODS}

\subsection{Carrying out of the study}

\subsubsection{Goal}

An LCA approach was used to examine the impact of increased materials and energy recovery from waste on human health and ecosystem quality. Two different scenarios were considered: a base scenario (S1) (Figure 1a); and a modified scenario (S2) (Figure 1b). Data were collected from the operation of an existing integrated waste treatment and recovery plant located in Arezzo, central Italy, with a population of about 99 thousand people. Table 1 shows the average composition of the MSW produced in the area. In the base scenario this plant processes about 100,000 tonnes per year of MSW and consists of three main sections: (1) an incinerator coupled with energy recovery operating at high efficiency; (2) a composting facility for recycling of the organic fraction from separated collection (OFSC) aimed at the production of organic fertilizer; and (3) a mechanical biological treatment plant. Of the about 100,000 tonnes/year of MSW treated, $85 \%$ enters the mechanical biological treatment (MBT), $46 \%$ is incinerated, 15\% (i.e. OFSC) composted, and 39\% landfilled (Table 2). Table 2 summarizes the mass flow balances of the base scenario (S1). In the modified scenario (S2) the current

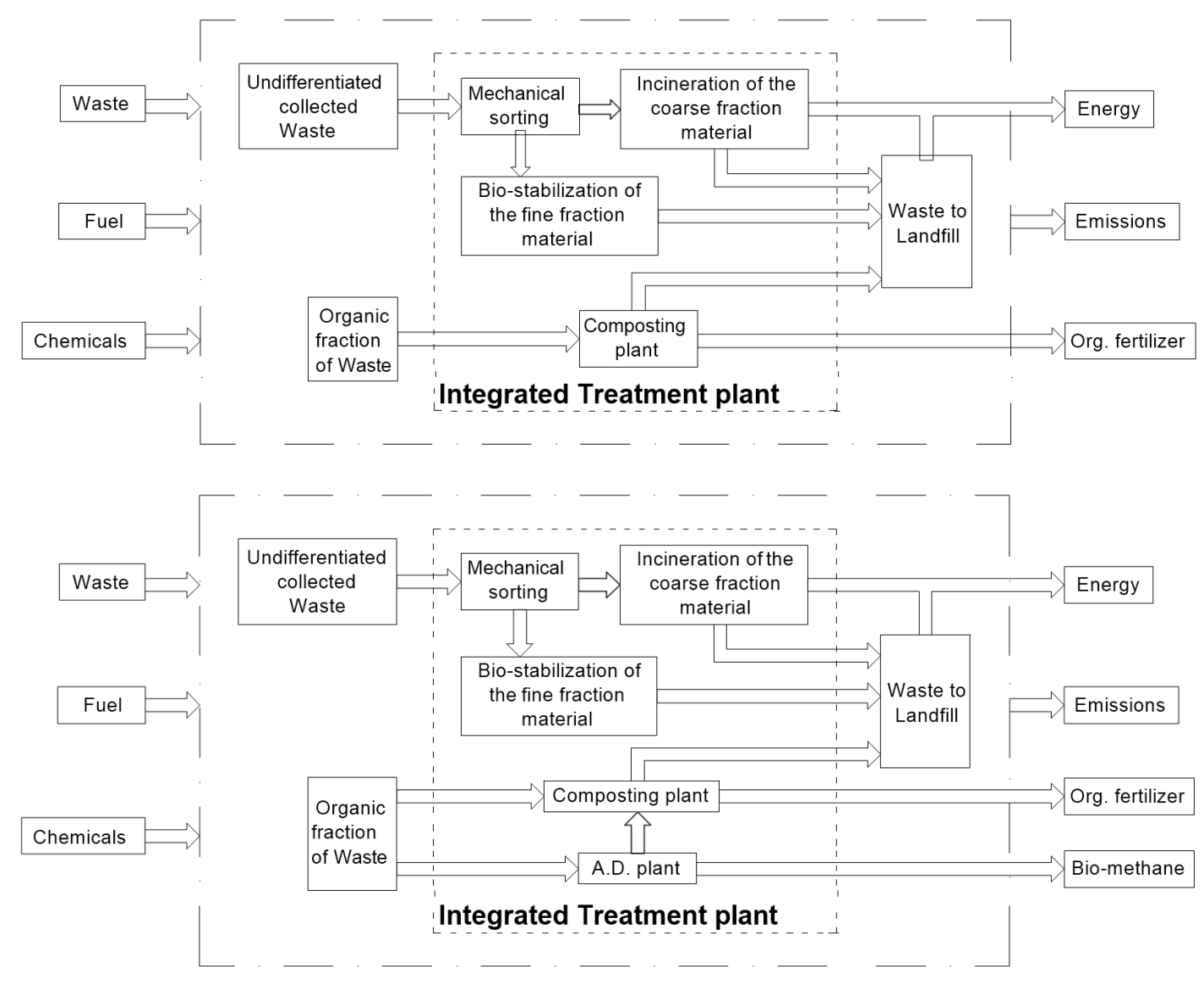

FIGURE 1: System boundaries of base-S1 (a) and modified-S2 (b) scenarios. 
TABLE 1: Average composition of the waste fractions produced in the city of Arezzo.

\begin{tabular}{l|c}
\hline Component & \% w/w \\
\hline Bio-waste & 35.0 \\
\hline Paper \& cardboard & 22.9 \\
\hline Plastic & 12.9 \\
\hline Metals & 2.70 \\
\hline Glass & 7.50 \\
\hline Wood & 3.00 \\
\hline WEEE & 0.80 \\
\hline Textile & 3.80 \\
\hline Street cleaning & 0.80 \\
\hline Nappies & \\
\hline Other & 3.70 \\
\hline
\end{tabular}

plant configuration was improved by introducing a new anaerobic digestion plant aimed at bio-methane recovery and increasing the treatment capacity of the composting section. In these new operating conditions the overall waste treated increased up to 143,000 tonnes/year of which $30 \%$ was incinerated, $40 \%$ recycled by composting ( $24 \%$ of which was pre-treated by $A D$ ) and $30 \%$ landfilled. The digestate from the $A D$, according to the current legislation, was post-composted for the production of an organic fertilizer. Emissions from waste transport from treatment facilities to the landfill were out of the scope of this study. The functional unit (FU) was the treatment of 1 tonne of waste aimed at maximizing its recycling and recovery rate. The FU was also assumed as the reference flow.

\subsubsection{Inventory analysis and Impact assessment}

The LCA was performed on the basis of literature data, direct observations and the Ecoinvent 3.0 (Wernet et al., 2016) database, appositely adjusted to the two scenarios. The boundary of the system was expanded to take into account the multi-functionality of the processes. Due to increase in the amount of waste treated, the life cycle inventory framework was consequential. SimaPro 8.5.2 (Goedkoop et al., 2016) was used for calculations. Avoided energy was considered to be natural gas, Italy, whereas the replaced raw materials (fertilizer) were evaluated on the basis of average EU market values. Furthermore, ISO 14040 (2006), ISO 14044 (2006) and ILCD Handbook (EC, 2012) guidelines were adopted. The ILCD 2011+ midpoint impact assessment method (EC, 2012) and the IMPACT 2002+ endpoint damage assessment were used. The impact categories chosen for the present study are reported in Table 3. In particular two damage categories and one impact category were considered concerning human health and ecosystem quality:

- Human Health $(\mathrm{HH})$ : damage expressed as Disability Adjusted Life Years (DALY), a parameter that shows the decrease in life expectancy because of premature death or permanent or temporary disability;

- Ecosystem Quality (EQ): damage expressed as Potentially Disappeared Fraction (PDF*m2*year) that is the percentage of species facing risk of extinction in a specific area in a specified period;

- Human Toxicity with cancer (HTc) and non-cancer (HTnc) effects expressed as a Comparative Toxic Unit for human toxicity impacts (CTUh), which is the estimated increase in morbidity.

\section{RESULTS AND DISCUSSION}

Figure 2 depicts the contribution of the different processes in the base and modified scenarios to the different damage categories, $\mathrm{HTnc}, \mathrm{HTc}, \mathrm{HH}$ and Ecosystem Quality, with their units of measurement per reference flow of 1 tonne of waste processed.

For Human Toxicity with non-cancer effects (Figure 2a), the modified scenario (S2) reflected $55 \%$ lower damage in comparison to the base scenario. This can be attributed to emissions from landfilling ( $58 \%)$, followed by incineration (23\%) and use on land of compost (18\%). On the other hand, landfilling was the major contributor ( 97\%) to the human toxicity with cancer effects, whereby the modified scenario showed $66 \%$ lower impact in comparison to the base scenario (S1) with a $16 \%$ higher fraction of waste landfilled (Figure 2a). Similarly, for the Human Health damage category, the modified scenario (S2) gave a $64 \%$ lower impact than

TABLE 2: Mass flow balances for the base and modified scenarios considering 1 tonne of waste processed.

\begin{tabular}{|c|c|c|c|c|}
\hline & & Base Scenario & Modified Scenario & \\
\hline Parameters & Process & Amount & Amount & Units \\
\hline Residual Municipal Solid Waste (RMSW) & Mechanical Sorting & 0.85 & 0.60 & Mass fraction \\
\hline Coarse fraction material & Incineration & 0.46 & 0.30 & Mass fraction \\
\hline Fine-fraction material & Bio-stabilization & 0.17 & 0.13 & Mass fraction \\
\hline \multirow{2}{*}{ Organic fraction from separated collection } & Composting & 0.15 & 0.16 & Mass fraction \\
\hline & A.D. & - & 0.24 & Mass fraction \\
\hline Waste of different treatments & Landfilling & 0.43 & 0.37 & Mass fraction \\
\hline Energy recovery & Incineration & 107 & 70 & kWhe \\
\hline Energy recovery & Landfill & 18.3 & 16 & kWhe \\
\hline Bio-methane & Upgrading of biogas & - & 17.2 & $\mathrm{Nm}^{3}$ \\
\hline Organic fertilizer & Use-on-land & 0.008 & 0.022 & Mass fraction \\
\hline
\end{tabular}



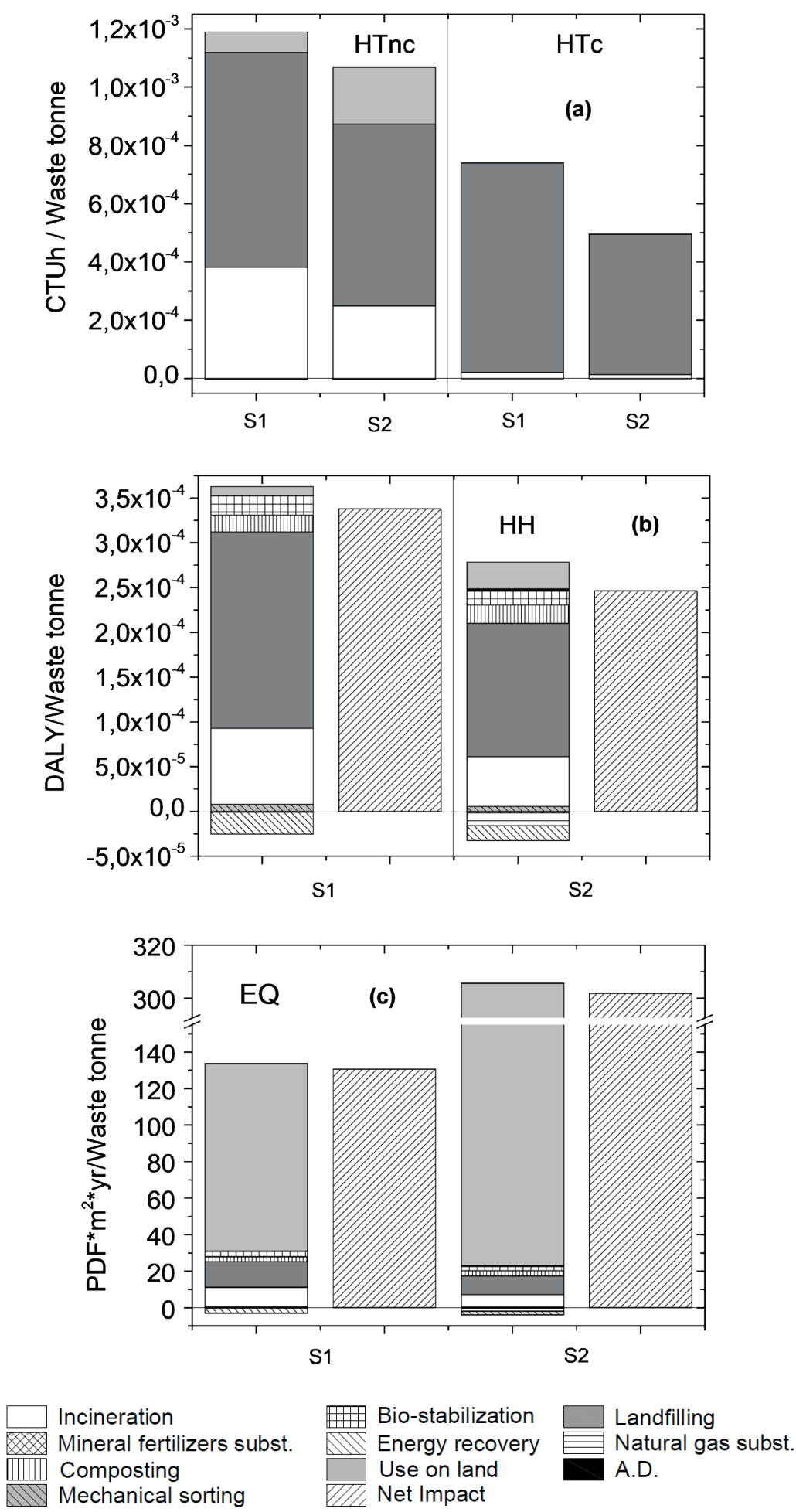

FIGURE 2: Contribution of base and modified scenarios to human toxicity non cancer (HTnc) and cancer (HTc) (a), human health (HH) (b) and ecosystem quality (EQ) (c).

the base scenario (S1) (Figure 2b). The emissions affecting this outcome were mainly from landfilling and incineration, whereas the modified scenario considered an increase in the recovery of OFSC for biological treatment, with $14 \%$ and $35 \%$ lower fractions of MSW landfilled and incinerated, respectively. In contrast, Ecosystem Quality was greatly affected by direct emissions from the organic fertilizer used on soil, which was nearly 4 times higher in the modified scenario than the base scenario. Accordingly, the modified scenario exhibited $15 \%$ higher impact in comparison to the base scenario (Figure 2c) due to soil pollution associated with the on-land use of compost (Table 4).

Shifting the reference flow from 1 tonne of waste to 1 tonne of mineral fertilizer $(\mathrm{N}, \mathrm{P}, \mathrm{K})$ effectively replaced 
by the composted OFSC, the values of ecosystem quality changed, indicating a lower ( $86 \%)$ impact for the modified scenario. This can be attributed to savings in emissions from substituting mineral fertilizer production. Note that the amount of substituted mineral fertilizers $\left(0.802 \times 10^{-3}\right.$ tonnes of mineral fertilizers/tonne of waste) in the modified scenario is nearly 4 times higher than the base scenario (Figure 3).

\section{CONCLUSIONS}

A life cycle assessment was conducted to evaluate potential Human Health and Ecosystem Quality impacts relative to the plan for expanding an existing integrated waste management facility by increasing the material and energy recovered. Base and modified scenarios were compared using three damage categories: Human Toxicity, Human Health, and Ecosystem Quality. The modified scenario considered an increase in the organic fraction from separated collection (OFSC) recovered for composting and anaerobic digestion coupled with bio-methane recovery, whereby lower fractions of waste are sent for incineration and landfilling in comparison to the base scenario. Increase in the recovery of the OFSC for biological treatment in the form of composting and anaerobic digestion resulted in lower Human Toxicity and Human Health damage. The latter was affected mainly by emissions from landfilling, which was the major contributor to the damage categories. In contrast, Ecosystem Quality exhibited a higher impact under the modified scenario in comparison to the base scenario mainly due to the greater amount of compost produced, that is, use on land, contributing to potential soil contamination including heavy metals. However, major savings can be achieved with the modified scenario if Ecosystem Quality is considered under the perspective of the substitution of mineral fertilizer by the organic fertilizer from OFSC. These results provide useful information in designing facility expansion by highlighting the impacts on Human Health and Ecosystem Quality due to increase in material and energy recovery.

\section{REFERENCES}

Arena, U., Mastellone, M.L., Perugini, F., 2003. The environmental performance of alternative solid waste management options: a life cycle assessment study. Chem. Eng. J. 96, 207-222.

Bonoli A., Cecchini F., De Robertis C., Franchini F., Menescardi S., Neri, P., 2004, Analisi del ciclo di vita di un termovalorizzatore: il caso Silla2 dell'AMSA Milano, Ente per le Nuove tecnologie, l'Energia e l'Ambiente (ENEA), Bologna.

Buttol, P., Masoni, P., Bonoli, A., Goldoni, S., Belladonna, V., Cavazzuti, C., 2007. LCA of integrated MSW management systems: case study of the Bologna district. Waste Manag. 27, 1059-1070.

Candela, S., Bonvicini, L., Ranzi, A., Baldacchini, F., Broccoli, S., Cordioli, M., et al., 2015. Exposure to emissions from municipal solid waste incinerators and miscarriages: a multisite study of the moniter project. Environ. Int. 78, 51-60.

Cangialosi, F., Intini, G., Liberti, L., Notarnicola, M., Stellacci, P., 2008. Health risk assessment of air emissions from a municipal solid waste incineration plant - a case study. Waste Manag. 28, 885895.

Cheng, H., Hu Yuanan, H., 2010. Municipal solid waste (MSW) as a renewable source of energy: Current and future practices in China. Bioresour. Technol. 101, 3816-3824.
TABLE 3: Impact categories related to the damage assessment of Human health and Ecosystem quality.

\begin{tabular}{|c|c|c|}
\hline Impact categories & Damage categories & Units of measure \\
\hline & Human Health & DALY \\
\hline Carcinogens & 0.0000028 & DALY / $\mathrm{kg} \mathrm{C}_{2} \mathrm{H}_{3} \mathrm{Cl}$ eq \\
\hline Non-carcinogens & 0.0000028 & DALY / $\mathrm{kg} \mathrm{C}_{2} \mathrm{H}_{3} \mathrm{Cl}$ eq \\
\hline Respiratory inorganics & 0.0007 & $\mathrm{DALY} / \mathrm{kg} \mathrm{PM} \mathrm{P}_{2.5} \mathrm{eq}$ \\
\hline lonizing radiation & $2.1 \mathrm{e}^{-10}$ & $\mathrm{DALY} / \mathrm{Bq} \mathrm{C}^{-14} \mathrm{eq}$ \\
\hline Ozone layer depletion & 0.00105 & $\mathrm{DALY} / \mathrm{kg} \mathrm{CFC}^{-11} \mathrm{eq}$ \\
\hline \multirow[t]{2}{*}{ Respiratory organics } & 0.00000213 & DALY / $\mathrm{kg} \mathrm{C}_{2} \mathrm{H}_{4}$ eq \\
\hline & Ecosystem Quality & PDF*m²*yr \\
\hline Aquatic ecotoxicity & 0.0000502 & PDF*m²*yr / kg TEG water \\
\hline Terrestrial ecotoxicity & 0.00791 & PDF $^{\star} m^{2 *} \mathrm{yr} / \mathrm{kg}$ TEG soil \\
\hline Terrestrial acid/nutri & 1.04 & $\mathrm{PDF}^{*} \mathrm{~m}^{2 *} \mathrm{yr} / \mathrm{kg} \mathrm{SO}_{2} \mathrm{eq}$ \\
\hline Land occupation & 1.09 & PDF* $m^{2 *} y r / m^{2}$ org.arable \\
\hline
\end{tabular}

TABLE 4: Percentage contributions of emissions related to use on land of 1 tonne of compost produced.

\begin{tabular}{|c|c|c|c|}
\hline \multicolumn{4}{|c|}{ Ecosystem Quality } \\
\hline Emissions & Compartment & Unit & (\%) \\
\hline Chromium & Soil & $\mathrm{PDF}^{*} \mathrm{~m}^{2 *} \mathrm{yr}$ & 3.68 \\
\hline Copper & Soil & $\mathrm{PDF}^{\star} \mathrm{m}^{2 \star} \mathrm{yr}$ & 36.52 \\
\hline Lead & Soil & $\mathrm{PDF}^{*} \mathrm{~m}^{2 *} \mathrm{yr}$ & 2.47 \\
\hline Nickel & Soil & $\mathrm{PDF}^{\star} \mathrm{m}^{2 \star} \mathrm{yr}$ & 2.73 \\
\hline Zinc & Soil & $\mathrm{PDF}^{*} \mathrm{~m}^{2 *} \mathrm{yr}$ & 53.76 \\
\hline Other substances & & $\mathrm{PDF}^{\star} \mathrm{m}^{2 *} \mathrm{yr}$ & 0.84 \\
\hline \multicolumn{4}{|c|}{ Human health } \\
\hline Emissions & Compartment & Unit & (\%) \\
\hline Ammonia & Air & DALY & 1.76 \\
\hline Cadmium & Soil & DALY & 1.50 \\
\hline Copper & Soil & DALY & 1.08 \\
\hline Zinc & Soil & DALY & 94.76 \\
\hline Other substances & & DALY & 0.90 \\
\hline
\end{tabular}

Only percentage contributions $>1 \%$ are reported in the Table.

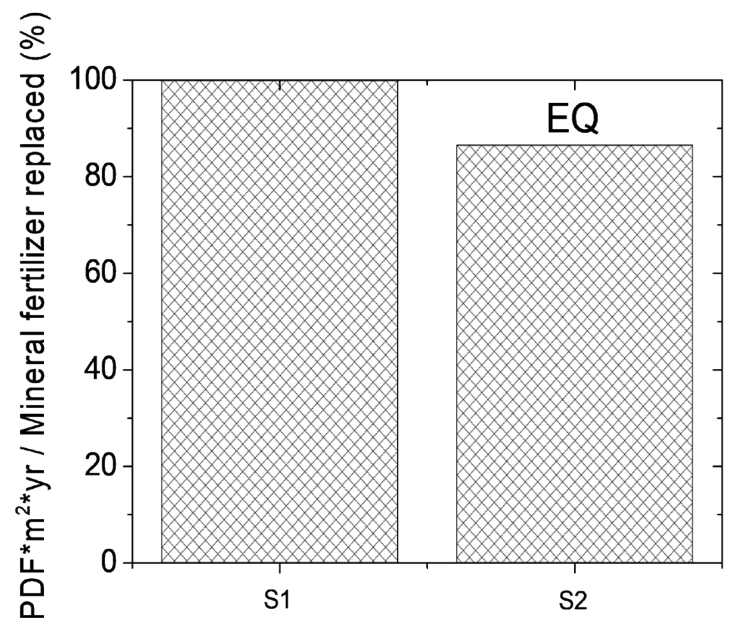

FIGURE 3: Normalized EQ per tonne of mineral fertilizers ( $N, P, K)$ replaced by the organic fraction separated prior to collection. 
Cherubini, F., Bargigli, S., Ulgiati, S., 2008. Life cycle assessment of urban waste management: energy performances and environmental impacts. The case of Rome, Italy. Waste Manag. 28, 2552-2564.

Deng, C., Xie, H., Ye, X., Zhang, H., Liu, M., Tong, Y., Ou, L., et al., 2016. Mercury risk assessment combining internal and external exposure methods for a population living near a municipal solid waste incinerator. Environ. Pollut. 219, 1060-1068.

Di Maria, D., \& Sisani, F. (2018). Effectiveness of municipal solid waste incinerators in replacing other fuels. A primary energy balance approach for the EU28. Waste Manag. Res. https:// doi:10.1177/0734242x18785737

Di Maria, F., Sisani, F., \& Contini, S. (2018). Are EU waste-to-energy technologies effective for exploiting the energy in bio-waste? Appl. Energ. 230, 1557-1572. https://doi:10.1016/j.apenergy.2018.09.007

EC-European Commission, 2012. Characterization Factors of the ILCD Recommended Life Cycle Impact Assessment Methods, Database and Supporting Information, first ed.. Joint Research Centre, Institute for Environment and Sustainability, Publications Office of the European Union, Luxembourg.

El-Fadel, M., Findikakis, A.N., Leckie, J.O., 1997. Environmental impacts of solid waste landfilling. J. Environ. Manage. 50, 1-25. http:// dx.doi.org/10.1006/jema.1995.0131

Goedkoop, M., Oele, M., Leijting, J., Ponsioen, T., Meijer, E. 2016. Introduction to LCA with SimaPro. Report version 5.2. Available at: <https://www.presustainability. com/download/SimaPro8IntroductionToLCA.pdf> (accessed 1012 2016).

Grosso, M., Motta, A., and Rigamonti, L., 2010. Efficiency of energy recovery from waste incineration, in the light of the new Waste Framework Directive. Waste Manag. 30, 1238-1243.

ISO 14040. 2006. Environmental Management: Life Cycle Assessment Principles and Guidelines. International Organization of Standardization, Geneva 2006

ISO 14044. 2006. Environmental Management: Life Cycle Assessment - Requirements and guidelines. International Organization of Standardization, Geneva 2006.

ISPRA (2018) Rapporto Rifiuti Urbani. Edizione 2018. ISPRA, Rapporti $297 / 2018$.

Karademir, A., 2004. Health risk assessment of PDD/F emissions from a hazardous and medical waste incinerator in Turkey. Environ. Int. 30, 1027-1038.

Liamsanguan, C., Gheewala, S.H., 2007. Environmental assessment of energy production from municipal solid waste incineration. Int. J. Life Cycle Assess. 12 (7), 536-539.
Ma, W., Tai, L., Qiao, Z., Zhong, L., Wang, Z., Fu, K., \& Chen, G., 2018. Contamination source apportionment and health risk assessment of heavy metals in soil around municipal solid waste incinerator: A case study in North China. Sci. Total Environ. 631-632, 348-357.

McDougall, F., White, P., Franke, M., 2001. Integrated Solid Waste Management: Life Cycle Inventory, second ed. Blackwell Science Ltd., Oxford, United Kingdom

Morselli, L., Luzi, J., De Robertis, C., Bassura, I., Carrillo, V., Passarini, F., 2007. Assessment and comparison of environmental performances of a regional incineration network. Waste Manag. 27, S85-S91.

Ni, W., Chenb, Y., Huang, Y., Wang, X., Zhang, G., Luo, J., et al., 2014. Hair mercury concentrations and associated factors in an electronic waste recycling area, Guiyu, China. Environ. Res. 128, 84-91.

Ranzi, A., Fustinoni, S., Erspamer, L., Campo, L., Gatti, M.G., Bechtold P., et al., 2013. Biomonitoring of the general population living near a modern solid waste incinerator: a pilot study in Modena, Italy. Environ. Int. 61, 88-97.

Reis, M.F., Sampaio, C., Brantes, A., Aniceto, P., Melim, M., Cardoso, L., et al., 2007. Human exposure to heavy metals in the vicinity of portuguese solid waste incinerators - part 1: biomonitoring of $\mathrm{Pb}$, $\mathrm{Cd}$ and $\mathrm{Hg}$ in blood of the general population. Int. J. Hyg. Environ. Health 210, 439-446.

Rigamonti, L., Grosso, M., Giugliano, M., 2009. Life cycle assessment for optimising the level of separated collection in integrated MSW management systems. Waste Manag. 29, 934-944.

Rovira, J., Nadal, M., Schuhmacher, M., Domingo, J.L., 2018, Concentrations of trace elements and PCDD/Fs around a municipal solid waste incinerator in Girona (Catalonia, Spain). Human health risks for the population living in the neighborhood. Total Environ. 630 $34-45$.

Schuhmacher, M., Domingo, J.L., Agramunt, M.C., Bocio, A., Muller, L., 2002. Biological monitoring of metals and organic substances in hazardous-waste incineration workers. Int. Arch. Occup. Environ. Health 75, 500-506.

Waste Framework Directive, 2008. Directive 2008/98/EC of the European Parliament and of the Council of 19 November 2008 on waste and repealing certain Directives. Off. J. Eur. Union L 312, 330. http://eur-lex.europa.eu/legal-content/EN/TXT/PDF/?uri=CELEX: 32008L0098\&from=EN

Wernet, G., Bauer, C., Steubing, B., Reinhard, J., Moreno-Ruiz, E., Weidema, B., 2016. The ecoinvent database version 3 (part I): overview and methodology. Int. J. Life Cycle Ass. 21 (9), 1218-1230 (accessed 1309 2016) 